\title{
Prueba del ADN y derecho a la intimidad: algunos conflictos concretos
}

DNA testing and the right to privacy: some specific conflicts

\section{Daniel Pérez González}

Investigador de GRIDES (Grupo de Investigación en Derecho Sanitario y Bioética, Observatorio de la Salud Pública de Cantabria, Fundación Marqués de Valdecilla). Asesor Jurídico de la Consejería de Sanidad y Servicios Sociales (Gobierno de Cantabria). Santander, España.

Resumen: La prueba del ADN constituye una importante herramienta en campos muy diversos, como el de la investigación criminal o la prueba de paternidad, debido a que permite la identificación de los individuos a través de sus respectivos perfiles de ADN. Sin embargo, la aplicación de las técnicas de la prueba del ADN afecta a los derechos fundamentales. El almacenamiento y uso de la información recopilada en las bases de datos de ADN o las intervenciones corporales pueden constituir, bajo determinadas circunstancias, una violación o limitación de los derechos fundamentales. Este artículo pretende estudiar determinados conflictos relativos a la prueba del ADN y el derecho a la intimidad.

Palabras clave: Prueba del ADN; derecho a la intimidad; investigación criminal; prueba de paternidad.

\begin{abstract}
DNA testing has become an important tool in different fields, such as criminal investigation or parental testing, in view of the fact that allows the identification of individuals by their respective DNA profiles. However, the implementation of DNA profiling techniques has implications for human rights. Storage and use of information compiled in DNA databases, or bodily intervention, may constitute, under certain circumstances, a violation or limitation of fundamental rights. This article aims to study certain conflicts dealing with DNA testing and the right to privacy.
\end{abstract}

Key words: DNA testing; right to privacy; criminal investigation; parental testing.

Resumo: O teste de DNA tornou-se uma importante ferramenta em campos tão diversos como o da investigação criminal ou a comprovação de paternidade, uma vez que permite a identificação dos indivíduos por meio de seus respectivos perfis genéticos. Entretanto, a aplicação dessas técnicas afeta direitos fundamentais. $O$ armazenamento e o uso da informação obtida nas bases de dados de DNA ou as intervenções corporais podem constituir, sob determinadas circunstâncias, violação ou limitação de direitos fundamentais. Este artículo analisa determinados conflitos relativos ao teste de DNA e ao direito à intimidade.

Palabras clave: Teste de DNA; direito à intimidade; investigação criminal; comprovação de paternidade. 


\section{Introducción}

El ácido desoxirribonucleico (en adelante $A D N$ ) es la molécula portadora de la información genética de cada célula humana y contiene el código genético de cada individuo. Tres son los caracteres que se derivan de esa información genética:

- $\quad$ el código genético es específico de cada individuo;

- $\quad$ el código genético es diferente en cada individuo;

- la la información genética es siempre la misma en cualquier célula de cada individuo.

En ese sentido, el análisis del ADN nos va a permitir hallar la huella genética del individuo, para lo cual podremos utilizar diferentes elementos del cuerpo humano, ya que el ADN lo podemos extraer del vello de un sujeto, de su saliva, de su sangre o en general de cualquiera de sus restos biológicos, y también de los restos biológicos presentes en prendas $u$ objetos, como pueden ser los cepillos, colillas, chicles etc. (Fernández Álvarez, 2006).

El desciframiento del ADN constituye un hito histórico del pasado siglo XX. En palabras de Stryer (2008, prologo) "la tecnología del DNA recombinante ha transformado profundamente a la Bioquímica. El genoma es hoy un libro abierto, del que puede leerse cualquier pasaje. El clonado y la secuenciación de millones de bases del DNA han enriquecido enormemente nuestros conocimientos sobre los genes y las proteínas [...] el ritmo de los descubrimientos en bioquímica ha sido, en estos últimos años, extraordinariamente rápido. Este progreso ha enriquecido grandemente nuestra comprensión de la base molecular de la vida y ha abierto nuevos campos de investigación".

En el caso concreto de la genética forense, explican Mestres Naval y VivesRego (2012) que la aparición de la denominada prueba del ADN ha supuesto una auténtica revolución para la investigación policial, los procesos judiciales y la propia sociedad. ${ }^{1}$ Asimismo, los mismos autores recuerdan que el descubrimiento de esta aplicación procesal del análisis del ADN se introduce por primera vez en el conocido como 'Caso Pichfork', proceso penal de mediados de los años ochenta del pasado siglo, y en el que la citada pericia posibilitó el descubrimiento del autor de dos crímenes, una vez comparado el respectivo perfil genético con las muestras

\footnotetext{
${ }^{1}$ Mestres Naval y Vives-Rego (2012, pág. 4) afirman que "la especialidad de la Genética Forense tiene algo más de un siglo, pero, con la incorporación de la denominada prueba del ADN hace casi tres décadas, se ha logrado una eficacia que ha revolucionado no solo la investigación policial y las sentencias jurídicas, si no que ha impactado positivamente a toda la sociedad moderna".
} 
obtenidas en el lugar de comisión de los delitos. Igualmente, cabe reseñar que el imparable avance tecnológico de las últimas décadas ha posibilitado la creación de bases de datos de individuos con el propósito o misión de facilitar la investigación y la persecución de delitos.

Pero las técnicas de identificación genética del ADN no solamente se utilizan en el ámbito de la represión criminal, sino que también se erigen como instrumento de indudable valía y probado éxito en otros campos. A modo de ejemplo, se utiliza para la determinación de las relaciones paterno-filiales, como técnica de reconocimiento de cadáveres y para la investigación de desaparecidos.

No obstante todo lo anterior, cabe recordar que se trata de una herramienta técnica que ha sido discutida doctrinal y judicialmente, y que origina una multiplicidad de debates entre los autores.

En el caso concreto de la investigación de delitos se discutía inicialmente su fiabilidad, su veracidad como criterio de identificación. A tal efecto, cabe traer a colación a la Sentencia de la Sala de lo Penal del Tribunal Supremo núm. 1701/1992, de 13 de julio (España, Tribunal Supremo, 1992), en la medida en que ponía en tela de juicio la infalibilidad de la prueba ${ }^{2}$. Hoy en día, sin embargo, como consecuencia de la profundización de los estudios sobre la estructura del ADN y la depuración de las técnicas que permiten su desciframiento ${ }^{3}$, la discusión se traslada a ámbitos diferentes. Las mayores controversias se centran posiblemente en torno a las relaciones que se traban con los derechos e intereses constitucionalmente reconocidos de aquellas personas afectadas por las técnicas que ahora se examinan. El debate se genera en consecuencia, no tanto ya desde la perspectiva de la eventual fiabilidad de la pericia - los estudiosos afirman con carácter generalizado que el porcentaje de acierto en la revelación de la identidad alcanza cifras elevadas ${ }^{4}-$, sino desde el ámbito de la relación y contraposición entre los diferentes derechos e

\footnotetext{
${ }^{2}$ Se expone en el Fundamento Jurídico $1^{\circ}$ de la sentencia que "el análisis del ADN medio probatorio que propuso, como se está diciendo, la defensa del acusado, declarada no procedente, lo fue porque está acreditado que dicha técnica estaba en período de experimentación (los avances científicos a veces espectaculares adelantan en progresión geométrica, muchas veces) (el paréntesis es nuestro) por lo que hasta ahora sus resultados no son fiables" (España, Tribunal Supremo, 1992).

3 A tal efecto, surgen en este ámbito agrupaciones de expertos con la finalidad de estandarizar u homogeneizar a nivel internacional los criterios de admisibilidad y fiabilidad de la prueba de ADN, como explica Álvarez de Neyra Kappler (2008, pág. 4-7).

${ }^{4}$ Fernández Álvarez (2006, pág. 1), alude a que "la prueba de ADN en los procesos de investigación de la paternidad alcanza una fiabilidad del 99,9\%", porcentaje elevado que habla muy a las claras de la efectividad y de la capacidad de la técnica para asegurar el resultado perseguido de identificación.
} 
intereses implicados en la aplicación de estas técnicas, públicos y privados, y por ende respecto de la interpretación de sus límites, ponderación y extensión.

El presente estudio analiza algunos de los problemas que derivan de la aplicación de las técnicas derivadas del descubrimiento del perfil genético de los individuos y su relación con el derecho a la intimidad. Y ello, porque posiblemente sea éste el derecho cuya integridad sufra mayores riesgos de una eventual vulneración con la aplicación de las técnicas de referencia, con independencia de recordar, que existen otros derechos que pueden resultar ser afectados (Soleto Muñoz y Fiororova, 2014).

\section{Derecho a la intimidad y pruebas del ADN}

El derecho a la intimidad supone excluir las intromisiones de los demás en la esfera de la vida personal y familiar, e integra o forma parte de los denominados derechos de la personalidad (España, Tribunal Constitucional, 1994a; España, Tribunal Constitucional, 2005). En ese sentido, se erige como un reducto construido alrededor de las personas que, en principio, nadie puede sacrificar y libre de interferencias, salvo las limitaciones derivadas de la naturaleza de todo derecho constitucional, fundamentalmente por su colisión con otros derechos constitucionales, y por su concurrencia con necesidades de interés general o público (Magdaleno Alegría, 2006; Aguiar de Luque, 1993; Brage Camazano, 2004).

Sobre la extensión o alcance del derecho a la intimidad, resume de manera ilustrativa Sánchez Caro las diferentes facetas del derecho, afirmando que "el derecho a la intimidad tiene diversas manifestaciones al considerar la intimidad como un estado o condición de acceso limitado a la persona, físico o corporal (intimidad física), a la información sobre la misma (intimidad sobre la información) o a determinadas decisiones (la llamada intimidad decisoria)" (Sánchez Caro, 2007, pág. $4)$.

Dentro del mismo, se incluye también el relativo a la intimidad genética, aspecto en el que es evidente la tensión con otros derechos como, por ejemplo, con el derecho a la identificación biológica o al conocimiento de la ascendencia paterna, problemática esta que se suscita en el campo específico del derecho civil. Sobre el concepto de intimidad genética, y en el campo de las pruebas de identificación genética del ADN, apunta Díez Rodríguez que "el concepto de intimidad es un concepto amplio [...] que admite una pluralidad de acepciones, y así junto al concepto 
de intimidad corporal [...] existe también como indicó la STC 207/1996 el concepto más amplio de intimidad personal [...] esta doble vertiente ha llevado a la distinción por parte de algún sector doctrinal entre la intimidad corporal y la intimidad genética, para referirnos con esta última a la que se ve vulnerada con cierto tipo de actuaciones por la razón de su finalidad, es decir por lo que a través de ella se pretenda averiguar, y que ya por sí solas constituyen una intromisión en el ámbito constitucional del derecho a la intimidad" (Díez Rodríguez, 2014, pág. 377).

En determinados supuestos - como en el proceso de investigación de los delitos -, la tensión se producirá entre el derecho individual a la intimidad del sujeto que sufre la investigación y el interés público encarnado en la necesidad de perseguir y castigar las conductas delictivas. En otros casos - como por ejemplo en los procesos de investigación de las relaciones paterno filiales -, el conflicto se produce entre el derecho a la intimidad y el derecho a conocer la identidad genética.

Sentado lo anterior, nos referiremos de manera concreta al ámbito de la averiguación y persecución de los delitos, deteniéndonos en determinadas cuestiones que se suscitan con la recogida de muestras de material genético por parte de las fuerzas policiales, así como a determinados aspectos relativos a las bases de datos de material genético policiales. Por otra parte, se efectuará una referencia a la investigación de las relaciones paterno filiales a través de los análisis de identificación genética del ADN.

\section{La recogida de muestras biológicas abandonadas practicada por la Policía}

Tal y como se indicaba previamente, la prueba del ADN y sus resultados se han mostrado especialmente provechosos en el marco de la investigación de delitos, dotando en consecuencia a las autoridades policiales y judiciales de un poderoso medio para el cumplimiento de sus funciones. Y ello, por cuanto la pericia posibilita la revelación de la identidad del individuo mediante la comparación de dos tipos de muestras biológicas: la que recabamos del cuerpo del investigado - muestra indubitada - y la que obtenemos en el lugar de comisión del delito (vello, restos de sangre, saliva, del cuerpo de la víctima o incluso de determinados terceros) - muestra dubitada. Ello supone que, una vez realizado el análisis del ADN, podemos obtener el perfil genético de ambas muestras, para concluir si existe o no correspondencia entre las muestras biológicas ("match" en terminología anglosajona), y para incorporar la 
misma como elemento probatorio del eventual proceso penal (Álvarez de Neira Kappler, 2008) ${ }^{5}$.

Pero igualmente merece destacarse que también genera numerosos problemas prácticos, máxime si tenemos en cuenta que concurren en este particular sector diferentes derechos e intereses implicados, tanto público como privados. Podemos citar a modo de ejemplo los relativos a la determinación de los sujetos habilitados para la recogida de las muestras, la eventual necesidad de que cuenten aquellos con una previa autorización judicial, la eficacia de la cadena de custodia de las muestras biológicas, los conflictos concernientes al consentimiento del interesado para la ejecución de la prueba, o incluso los referentes a la formación científica del juez encargado del caso.

En este punto, nos referiremos al problema específico derivado de la recogida de las muestras biológicas abandonadas, efectuada por las fuerzas policiales y $\sin$ una previa autorización judicial, para lo que se analizan, por su interés, dos sentencias del Tribunal Supremo.

Se trata de dos sentencias cercanas en el tiempo, y que abordan supuestos de hecho aparentemente análogos. Pese a ello, la argumentación utilizada no es coincidente, llegando a pronunciamientos distintos, lo que ha llevado a Narváez Rodríguez a calificar la actuación del órgano judicial como "contradictoria jurisprudencia del Tribunal Supremo" (Narváez Rodríguez, 2006). Ambos casos están relacionados con los actos de violencia callejera del entorno de la banda terrorista ETA. La obtención del elemento de prueba es ajena al conocimiento del sujeto, pero posiblemente necesaria para evitar la pérdida de la misma en el caso de que sea preceptivo recabar con carácter previo la autorización judicial pertinente. La primera de ellas es la Sentencia de la Sala de lo Penal del Tribunal Supremo de fecha 19 de abril de 2005 (España, Tribunal Supremo, 2005b), la segunda la Sentencia de la misma Sala de fecha 14 de octubre del mismo año (España, Tribunal Supremo, 2005a).

La Sentencia de 19 de abril concluye que la prueba así obtenida era ilícita, puesto que no concurre en el supuesto ni el consentimiento del sujeto afectado, ni tampoco una previa autorización del juez a la policía para la recogida de los restos biológicos (la segunda muestra biológica se obtiene de un esputo del detenido

\footnotetext{
${ }^{5}$ La Sentencia de la Sala de lo Penal del Tribunal Supremo núm. 1701/1992, de 13 de julio, distingue en el mismo sentido entre material indubitado - constituido por el material genético del acusado - y material dubitado - el hallado en el cuerpo de la víctima (España, Tribunal Supremo, 1992).
} 
arrojado en las dependencias policiales). El Tribunal llega a la conclusión de que se ha producido una vulneración del derecho al proceso - conculcación del derecho constitucional a la presunción de inocencia -, habida cuenta de que no se ha garantizado la autenticidad de la prueba (España, Tribunal Supremo, 2005b).

A conclusiones diferentes llega la Sentencia del mismo órgano judicial de 14 de octubre del mismo año. El pronunciamiento judicial afirma que no se origina afectación de los derechos constitucionales del detenido, tampoco del derecho a la intimidad, por lo que califica como ajustada a derecho la aprehensión del material biológico del detenido en sede policial, aprehensión que igualmente se había efectuado sin que concurriera una previa habilitación judicial para la recogida, y sin que se hubiera otorgado consentimiento por el afectado, que en realidad no era consciente de que se hubiera obtenido aquel material genético (España, Tribunal Supremo, 2005a).

Posiblemente, para evitar problemas como el citado en relación con la intervención policial y otros similares que pudieran surgir acerca de su participación en el seno de la investigación judicial, el Pleno de la Sala Segunda del Tribunal Supremo adopta el Acuerdo de 31 de enero de 2006, zanjando las dudas suscitadas al disponer que "la Policía Judicial puede recoger restos genéticos o muestras biológicas abandonadas por el sospechoso sin necesidad de autorización judicial" (España, Tribunal Supremo, 2006).

Aquella Sentencia de 14 de octubre de 2005 (España, Tribunal Supremo, 2005a) fue posteriormente recurrida en amparo ante el Tribunal Constitucional, que mediante Sentencia núm. 199/2013, de 5 de diciembre, desestima la demanda (se formulan dos votos particulares a la sentencia, manifestando su discrepancia con la fundamentación y el fallo) (España, Tribunal Constitucional, 2013). La sentencia analiza las cuestiones que se suscitan en torno a la recogida de la muestra genética a la luz de su propia jurisprudencia, y concluye que en el caso objeto de estudio no se produce vulneración alguna de derechos constitucionales. En su razonamiento, cita a las dos sentencias y al acuerdo arriba mencionados, manifestando que el cambio de criterio operado por la Sentencia de octubre, descansa en el carácter voluntario "del abandono del sustrato biológico (saliva)", el cual no se había considerado por la de abril (Fundamento Jurídico Segundo); criterio éste, que también acoge para descartar que se origine una conculcación del derecho a no declarar contra sí mismo y a no 
confesarse culpable, al no haberse empleado vis física o moral (Fundamento Jurídico Cuarto).

En lo que hace a la eventual vulneración del derecho a la intimidad (personal) por la realización de la prueba del ADN, manifiesta el Tribunal Constitucional que "supuso una injerencia en su derecho a la intimidad por su mera puesta en riesgo", si bien inmediatamente añade que resulta necesario examinar si la misma se ha producido o no de "forma constitucionalmente conforme" (Fundamento Jurídico Séptimo). A tal efecto, examina y declara que concurren los requisitos que justifican la injerencia en el derecho a la intimidad: existencia de un fin constitucionalmente legítimo (investigación del delito), cobertura legal de la pericia, necesidad de autorización judicial, y respeto al principio de proporcionalidad. En el caso de la autorización judicial, advierte que concurren circunstancias excepcionales que justifican que aunque el análisis no fue ordenado judicialmente, no se lesionó el derecho fundamental, debido a la escasa incidencia material en la intimidad personal del sujeto, a que la prueba se ciñó al "ADN no codificante", que era necesaria una actuación urgente, que la normativa aplicable no la preveía con carácter necesario, y que se aportó al proceso el resultado del análisis en cuanto estuvo disponible. Niega también que se vulnere el derecho a la autodeterminación informativa, toda vez que el perfil de ADN fue obtenido con "fines identificativos a la vista de las regiones de ADN no codificante", y que no consta que haya sido utilizado para finalidad distinta, ni que haya sido objeto de cesión o tratamiento distinto (España, Tribunal Constitucional, 2013).

\section{Bases de datos policiales de ADN}

Indicábamos previamente que el moderno desarrollo de la tecnología relacionada con el $A D N$ ha facilitado la creación de bases de datos que recopilan los datos genéticos de los individuos, con el propósito o finalidad de colaborar en la investigación y represión de los delitos. Así, expone García Mansilla (2010) que, en países como Inglaterra, Estados Unidos o Canadá, arrestados, procesados y condenados por la comisión de un delito están obligados a someterse a una prueba de extracción de muestra biológica para obtener su perfil de ADN, el cual a su vez se almacena en una base de datos gubernamental. Paralelamente, se forman bases que contienen datos de ADN obtenidos del análisis forense de evidencias recogidas en la escena del crimen, lo que posibilita la comparación de perfiles y eventualmente la 
identificación del presunto delincuente (y del inocente). De acuerdo con una encuesta de Interpol de 2008, 120 países utilizan la prueba de ADN en investigaciones criminales, 54 tienen bases de datos de ADN y 26 están estudiando su creación (Soleto Muñoz y Fiodorova, 2014, pág. 150). En ese sentido, las bases de datos de ADN constituyen una fenomenal arma con la que se dotan las autoridades de los Estados para combatir la delincuencia.

Sin embargo, no es menos cierto que nos encontramos ante un campo especialmente complejo, en el que surgen problemas de naturaleza ética y legal, y que genera "intensos debates académicos y políticos" (García Mansilla, 2010, pág. 5).

García Mansilla pone de relieve el debate sobre la necesidad o no de incrementar el uso de información genética por los Estados, así como la necesidad de definir con precisión el alcance de la protección del derecho a la privacidad de este tipo de información. Señala asimismo la importancia de definir con precisión el derecho a la privacidad o intimidad de la información genética, y que "toda iniciativa gubernamental relacionada con el genoma tendría que tener como límite preciso y necesario el respeto a la integridad corporal de las personas, así como la protección de la información sensible que contiene el ADN y que confiere características unidas al derecho a la intimidad o privacidad de la información genética" (García Mansilla, 2010, pág. 6).

La incidencia sobre los derechos de los individuos puede producirse no sólo en el mismo momento en el que se práctica la prueba de ADN - piénsese, por ejemplo, en un análisis corporal que tiene una relevancia clara en relación con la intimidad personal corporal, como puede ser en el caso de un examen ginecológico -, sino también en un momento ulterior, con la eventual propagación o difusión de datos personales recogidos en una base de datos y no consentida por el interesado - por ejemplo con la publicidad de los datos personales obtenidos con la práctica de la pericia.

En este sentido, y tal y como ponen de manifiesto Soleto Muñoz y Fiodorova (2014), la eventual colisión con los derechos se puede originar en las diferentes fases en las que se utilizan las técnicas de identificación relacionadas con el desciframiento de los datos del ADN. No debe olvidarse tampoco que la información recopilada en las bases de datos es de naturaleza especialmente sensible, en la medida en que contienen información genética y biológica de la persona. 
Sierra Fernández, en comentario a la Ley Orgánica 10/2007, de 8 de octubre, reguladora de la base de datos policiales sobre identificadores obtenidos a partir del $A D N$, destaca que en los procesos de almacenamiento y control, puede resultar afectados el derecho constitucional a la intimidad, así como el derecho a la protección de los datos de carácter personal. ${ }^{6} \mathrm{Y}$ estos, junto a otros como el derecho a la libertad, a la salud y a la integridad física, se van a colocar enfrente de otros no menos importantes, como el derecho a la tutela judicial efectiva y el interés público en la persecución y averiguación de los delitos.

Resulta necesario pues, alcanzar un equilibrio de fuerzas entre los diferentes intereses concurrentes en este campo. Esto es, si bien parece lógico dotar a las autoridades competentes de los medios necesarios para cumplir sus fines - máxime en el delicado espectro de la persecución del crimen -, también resulta necesario adoptar aquellas medidas que resulten precisas para salvaguardar los derechos e intereses que pueden verse comprometidos.

En el caso de España, mediante la Ley Orgánica 10/2007, se crea una base de datos policial centralizada que integra los ficheros de titularidad de las Fuerzas y Cuerpos de Seguridad del Estado "tanto para la investigación y averiguación de delitos, como para los procedimientos de identificación de restos cadavéricos o de averiguación de personas desaparecidas" (artículo 1 1) $^{7}$. Su parte expositiva razona que se parte de la exigencia de la sociedad, de que autoridades policiales y judiciales se doten de aquellos instrumentos precisos para la lucha contra los crímenes "que generan mayor alarma social". E inmediatamente después expone, que en su redacción se han tenido en consideración los criterios doctrinales del Tribunal Constitucional, sobre protección de derechos fundamentales en la obtención de pruebas a partir de los perfiles de ADN.

A tal efecto, la norma establece un conjunto de garantías. Así, dispone su artículo 4 que "sólo podrán inscribirse identificadores obtenidos a partir del ADN [...]

\footnotetext{
${ }^{6}$ Sierra Fernández explica que "se ponía de manifiesto la importancia de los datos derivados del análisis del ADN, ya que esos datos, no solo tienen una finalidad de identificación, sino que, además, y con mayor amplitud, nos determina toda la información genética de una persona y, con ello, a la vista del avance de las investigaciones, nos facilita, y puede en un futuro facilitar, datos y aspectos que afectan de forma clara y evidente a la intimidad de la persona" (Sierra Fernández, 2008, pág. 1).

${ }^{7}$ No todo tipo de delitos; la ley se circunscribe a los restos biológicos del sospechoso, detenido o imputado cuando se trate de delitos graves, y en todo caso los que afecten a la vida, la libertad, la indemnidad o la libertad sexual, la integridad de las personas y el patrimonio (si realizados con fuerza en las cosas o violencia o intimidación en las personas), incluyendo asimismo a los casos de delincuencia organizada. La norma señala que también serán inscribibles los datos cuando el afectado hubiera prestado expresamente su consentimiento.
} 
que proporcionen, exclusivamente, información genética reveladora de la identidad de la persona y de su sexo" (la doctrina tradicional suele distinguir entre "ADN codificante o expresivo" y "ADN basura o no codificante" (Díez Rodríguez, 2014, pág. 368), lo que excluye los de naturaleza codificante que permiten revelar otro dato o característica genética. Por su parte, los artículos 5 y 6 disponen que las muestras deben remitirse por la Policía Judicial a los laboratorios acreditados (por la Comisión Nacional para el uso forense del ADN, quedando sometidos a controles periódicos de calidad), a quienes se encomienda en exclusiva efectuar el análisis del ADN, y que corresponde a la autoridad judicial pronunciarse sobre su ulterior conservación. El artículo 7 impone una serie de cautelas en relación con el uso y cesión de los datos, habida cuenta de su especial naturaleza; de modo, que se determina que los datos sólo se podrán utilizar por las Unidades de Policía Judicial de las Fuerzas y Cuerpos de Seguridad del Estado, por las Autoridades Judiciales y Fiscales, en la investigación de los delitos a los que se refiere la norma.

En el caso de identificación de cadáveres o averiguación de personas desaparecidas, los datos de la base sólo se podrán utilizar en la investigación para la que fueron obtenidos. En lo que hace a la cesión de los datos, se permite a las Autoridades Judiciales, Fiscales o Policiales de terceros países de acuerdo con los convenios internacionales vigentes ratificados por España; a las Policías Autonómicas; y al Centro Nacional de Inteligencia. Además, todos los ficheros están sometidos al nivel de seguridad alto, en los términos previstos en la Ley Orgánica 15/1999, de 13 de diciembre, de Protección de Datos de Carácter Personal, disciplinando el artículo 9 un régimen de conservación, cancelación, rectificación y acceso a los datos.

La eventual afectación del derecho a la intimidad derivada de la conservación y almacenamiento de muestras biológicas y perfiles de ADN, fue objeto de análisis por el Tribunal Constitucional en la sentencia previamente citada núm. 199/2013 (España, Tribunal Constitucional, 2013), que, a su vez, se remite a la doctrina del Tribunal Europeo de Derechos Humanos contenida en la Sentencia de 4 de diciembre de 2008, caso S. y Marper c. Reino Unido (Tribunal Europeo de Derechos Humanos, 2008) y en la decisión de inadmisión de 7 de diciembre de 2006, en el caso Van der Velden c. Países Bajos (Tribunal Europeo de Derechos Humanos, 2006).

Esta última sentencia analiza un supuesto de conservación indefinida de huellas dactilares, muestras celulares y perfiles de ADN una vez concluido el juicio sin 
condena, razonando que el tratamiento informatizado de los perfiles de ADN habilita para ir más allá de una mera identificación neutra, ya que permite realizar estudios de investigación familiar para descubrir vínculos genéticos entre personas y su origen étnico, cualidades que resultan susceptibles de lesionar el derecho a la vida privada (su conservación constituye una lesión de ésta). La decisión de inadmisión examina la conservación del ADN de un condenado por un grave delito, en una base de datos destinada a la prevención de delitos, y concluye que el uso potencial y futuro del material biológico excede del ámbito de la identificación neutra y es suficientemente invasiva para considerarla intromisión en la vida privada.

A partir de la citada doctrina, el Tribunal Constitucional expone que "el peligro potencial de revelación o acceso a datos que inciden en la intimidad personal constituye en sí mismo una injerencia en el derecho a la vida privada" (España, Tribunal Constitucional, 2013). En el supuesto concreto, recordamos que el Tribunal Constitucional no apreció vulneración de los derechos del demandante, puesto que los datos obtenidos se utilizaron exclusivamente con pretensiones identificativas en el marco de la persecución de un delito, sin que constase que se hubiera efectuado su incorporación a una base de datos; si bien, aclara el fallo judicial que "nada impediría al demandante reaccionar contra esa pretendida e hipotética conservación de su perfil de ADN solicitando su eliminación del perfil de la base de datos a la que afirma que se incorporaron" (España, Tribunal Constitucional, 2013). En el mismo sentido, es la Sentencia del Tribunal Constitucional núm. 15/2014, de 30 de enero (España, Tribunal Constitucional, 2014).

Sin perjuicio de lo anterior, cabe referir que Díez Rodríguez introduce una reflexión interesante en torno al denominado "ADN basura o no codificante", informando que recientemente y como consecuencia del avance científico en este campo - puesto de manifestó por un grupo de investigadores en la Encyclopedia of DNA Elements - se ha descubierto la "incidencia directa de la parte de ADN que esencialmente se venía utilizando en la identificación de delincuentes como reveladora de datos concernientes a la salud del sujeto" (Díez Rodríguez, 2014, págs. 369 y seg.). Y en ese sentido, propone una modificación de la Ley Orgánica 10/2007, de manera que se adapte o coordine con los citados descubrimientos técnicos, en la medida en que pudieran resultar afectados los derechos fundamentales.

Cabe advertir igualmente, que la ya citada Sentencia del Tribunal Constitucional núm. 199/2013 precisamente utilizaba como criterio argumental para 
concluir que no había conculcación de los derechos del demandante, que la actuación pericial se había ceñido a las regiones de ADN no codificante (de acuerdo con los estándares proporcionados por la normativa nacional e internacional que cita).

\section{Las pruebas de investigación de la paternidad}

Como se adelantaba previamente, las técnicas de desciframiento del ADN se utilizan también en el campo de la investigación de la paternidad genética. El derecho a conocer el origen biológico, tal y como indica Ruiz Sáenz ${ }^{8}$, se consagra tanto en la Constitución Española, que en su artículo 39.3, y en el marco de la obligación de protección integral de los hijos, señala que "la ley posibilitará la investigación de la paternidad", como en la Ley 1/2000, de 7 de enero, de Enjuiciamiento Civil, que en su artículo 767.2 dispone que "en los juicios sobre filiación será admisible la investigación de la paternidad y de la maternidad mediante toda clase de pruebas, incluidas las biológicas".

Pero tampoco es este un campo ajeno a la controversia. Así, se presenta un conflicto entre derechos de manera recurrente, cuando la pretensión del niño de conocer su origen biológico se enfrenta con la negativa del presunto progenitor a someterse a la prueba de paternidad. Frente al derecho del primero a conocer quién es su padre o su madre, se opone el derecho de aquéllos a preservar su intimidad, con lo cual se plantea la delicada cuestión de cuál de los dos derechos ha de prevalecer frente al otro.

Este conflicto fue abordado por la Sentencia del Tribunal Constitucional num. 7/1994, de 17 de enero, que analizaba un supuesto de negativa a la práctica de la prueba biológica (extracción de sangre), invocando los derechos a integridad física y moral, y a la intimidad personal.

El tribunal no admite la referida pretensión, afirmando que no existe conculcación de derechos, teniendo en cuenta que se trata de una prueba prevista legalmente y que se ha acordado razonadamente por la autoridad judicial. En consecuencia, resúelve la controversia entre derechos dando prevalencia al interés social y de orden público que subyace en las declaraciones de paternidad. Señala su Fundamento Jurídico $3^{\circ}$ que "se produce una colisión entre los derechos

\footnotetext{
${ }^{8}$ Ruiz Sáenz (2013, págs. 152-153), expone que también se han aducido como fundamento del referido derecho los preceptos constitucionales relativos a la dignidad de la persona y el libre desarrollo de la personalidad previsto en el artículo 10, el principio de igualdad del artículo 14, o el derecho a la integridad moral que consagra el artículo 15.
} 
fundamentales de las distintas partes implicadas; y que no hay duda de que, en los supuestos de filiación, prevalece el interés social y de orden público que subyace en las declaraciones de paternidad, en las que están en juego los derechos de alimentos y sucesorios de los hijos, objeto de especial protección por el art. 39.2 CE, lo que trasciende a los derechos alegados por el individuo afectado, cuando está en juego además la certeza de un pronunciamiento judicial. Sin que los derechos constitucionales a la intimidad, y a la integridad física, puedan convertirse en una suerte de consagración de la impunidad, con desconocimiento de las cargas y deberes resultantes de una conducta que tiene una íntima relación con el respeto de posibles vínculos familiares" (España, Tribunal Constitucional, 1994 b).

Ahora bien, impone seguidamente una serie de garantías obligatorias que debe seguir la práctica de la prueba de paternidad, al "consistir en una intromisión en el ámbito protegido del ciudadano". En ese sentido, afirma que la finalidad de permitir la práctica de la prueba biológica es la defensa de los intereses del hijo; que la prueba de paternidad (que conlleva una intervención corporal) no resulta obligatoria si la evidencia puede obtenerse a través de otros medios menos lesivos para la integridad física; que no procede acordar su práctica cuando comporta un grave riesgo o quebranto para la salud (por ello se efectuará por personal sanitario en centros hospitalarios públicos); y, finalmente, que la medida judicial que la ordena, debe guardar una adecuada proporción entre la intromisión que conlleva en los derechos del afectado, y la finalidad a la que sirve (motivación de la necesidad de la medida).

En cuanto al eventual derecho a negarse a la prueba de paternidad, la referida sentencia dispone que de acuerdo con las anteriores coordenadas, tal negativa solamente sería legítima si no existieran "indicios serios de la conducta que se le atribuye", o bien pudiera provocarse "un gravísimo quebranto para su salud", remitiéndose a las precauciones que establecía la normativa vigente en ese momento en favor de los derechos fundamentales del sujeto (necesidad de presentar con la demanda un principio de prueba de los hechos, a la luz del artículo 127.2 del Código Civil; $y$, criterio de que las pruebas biológicas sólo proceden si no son impertinentes o inútiles, según el artículo 566 de la Ley de Enjuiciamiento Civil) (España, Tribunal Constitucional, 1994 b).

En este punto, recuerda la Sentencia del Tribunal Constitucional núm. 177/2007, de 23 de julio (España, Tribunal Constitucional, 2007), que la doctrina de la sentencia de 1994 acerca de los límites a la investigación de la paternidad tuvo eco 
en la redacción del artículo 767.4 de la Ley 1/2000, de Enjuiciamiento Civil, precepto que postula que: "la negativa injustificada a someterse a la prueba biológica de paternidad o maternidad permitirá al Tribunal declarar la filiación reclamada, siempre que existan otros indicios de la paternidad o maternidad y la prueba de ésta no se haya obtenido por otros medios" (Magro Servet, 2010; Pulido Quecedo, 2007; Mondéjar Peña, 2006).

Finalmente, debe advertirse que el derecho a la investigación de la paternidad presenta una excepción en la legislación española sobre reproducción humana asistida (Ley 14/2006, de 26 de mayo), ya que prevé el anonimato de los donantes, dando prevalencia al derecho a la intimidad sobre el derecho a conocer el origen biológico; previsión que no obstante, ha sido criticada por cierto sector doctrinal, que aduce dudas de constitucionalidad en torno a la misma (Ruiz Sáenz, 2013; Romero Coloma, 2009). En cualquier caso, cabe advertir que la figura del anonimato del donante ha sido avalada por el Tribunal Constitucional en su Sentencia núm. 116/1999, de 17 de junio de 1999 (que enjuiciaba la citada previsión contenida en la Ley 35/1988, de 22 de noviembre) (España, Tribunal Constitucional, 1999).

\section{Referencias}

AGUIAR DE LUQUE, L. Los límites de los derechos fundamentales. Revista del Centro de Estudios Constitucionales, (14):9-34, 1993. ISSN 0214-6185.

ÁLVAREZ DE NEYRA KAPPLER, S. La prueba de $A D N$ en el proceso penal. Granada: Editorial Comares, 2008. ISBN 9788498364064.

BRAGE CAMAZANO, J. Los límites a los derechos fundamentales. Madrid: Dykinson; 2004. ISBN 9788497725149.

DíEZ RODRÍGUEZ, J. R. Pruebas del ADN e intimidad genética: aspectos mejorables de la actual regulación (I). Actualidad del Derecho Sanitario, (215):365-381, Mayo 2014. ISSN 1136-6869.

FERNÁNDEZ ÁLVAREZ, B. Mạ. El ADN desde una perspectiva penal. [s.I.] [s.n.], Diciembre 2006 [on line] Disponible en: http://noticias.juridicas.com/articulos/55-DerechoPenal/200612-11156578461200.html [Consulta el 16 jun. 2014]. [ISBN no proveído]

GARCÍA MANSILLA, M. J. Bases de datos de ADN y derecho a la privacidad genética. [s.I.] [s.n.], 2010. [on line] Disponible en: http://www.ancmyp.org.ar/user/files/04Garcia\%20Mansilla.pdf [Consulta el 18 de agosto de 2014]. [ISBN no proveído]

MAGDALENO ALEGRÍA, A. Los límites de las libertades de expresión e información en el Estado Social y Democrático de Derecho. Madrid: Colección Monografías. Congreso de los Diputados; 2006. ISBN-84-7943-288-8.

MAGRO SERVET, V. La prueba de indicios en el proceso civil. Respuesta de los tribunales. Revista de Jurisprudencia El Derecho, (3):6. Jul. 2010. [ISBN no proveído] 
MESTRES NAVAL F. y VIVES-REGO, J. La resolución de casos abiertos, exoneraciones y análisis familiares por medio de la genética avanzada. Aspectos forenses, sociales y éticos. Revista Electrónica de Ciencia Penal y Criminología 4:1-4, 18, sep. 2012. ISSN 1695-0194. [on line] Disponible en: http://criminet.ugr.es/recpc/14/recpc14-04.pdf [Consulta el 17 sep. 2014].

MONDÉJAR PEÑA, Mà . I. Valoración de la negativa injustificada a someterse a las pruebas biológicas de paternidad. Diario de Jurisprudencia El Derecho, (2243):1. Mar. 2006. [ISBN no proveído]

NARVÁEZ RODRÍGUEZ, A. La recogida de muestras biológicas la contradictoria jurisprudencia del Tribunal Supremo. Actualidad Jurídica Aranzadi, (703):1-4, 2006. ISSN 1132-0257.

PULIDO QUECEDO, M. De nuevo sobre las pruebas de investigación de paternidad. Repertorio Aranzadi del Tribunal Constitucional, (12): 9-12, 2007. ISSN 0212-2855.

ROMERO COLOMA, A. Mํ. La identidad genética y la intimidad: un conflicto de derechos. Actualidad Jurídica Aranzadi, (789): 10-13, 2009. ISSN 1132-0257.

RUIZ SÁENZ, A. El anonimato del donante en los supuestos de reproducción humana asistida. Derecho y Salud, 23(E): 152-158, 2013. ISSN 1133-7400.

SÁNCHEZ CARO, J. Intimidad y secreto médico en el derecho español. [s.I.] [s.n.], 2007. [on line] Disponible en: http://www.peritajedrsuperby.es/alejandrosuperby secreto medico.htm [Consulta el $15 \mathrm{de}$ abril de 2013]. [ISBN no proveído]

SIERRA FERNÁNDEZ, J. Bases de datos policiales sobre identificadores obtenidos a partir del AND, la nueva normativa aplicable. Revista de Jurisprudencia El Derecho, (4):1, abr. 2008. [ISBN no proveído]

SOLETO MUÑOZ, H. y FIODOROVA, A. DNA and law enforcement in the European Union: tools and Human Rights Protection. Utrech Law Review, 10(1):149-162, jan. 2014. ISSN 1871-515-X.

STRYER, L. Bioquímica. (3. ed.) Barcelona-Bogotá-Buenos Aires-Caracas-México: Editorial Reverté, 1988. ISBN-84-291-7575-X.

\section{Referencias Jurisprudenciales}

ESPAÑA. Tribunal Constitucional (Pleno). Sentencia núm. 15/2014. Recurso de amparo 10618-2006. Ponente: Valdés Dal-Re, F. Madrid, 30 de enero de 2014.

ESPAÑA. Tribunal Constitucional (Pleno). Sentencia núm. 199/2013. Recurso de amparo 9530-2005. Ponente: Pérez de los Cobos Orihuel, F. Madrid, 5 de diciembre de 2013.

ESPAÑA. Tribunal Constitucional (Sala Primera). Sentencia núm. 177/2007. Recurso de amparo 6276-2005. Ponente: Aragón Reyes, M. Madrid, 23 de julio de 2007.

ESPAÑA. Tribunal Constitucional (Sala Primera). Sentencia núm. 25/2005. Recurso de amparo 2123-2001. Ponente: Rodríguez-Zapata Pérez, J. Madrid, 14 de febrero de 2005.

ESPAÑA. Tribunal Constitucional (Pleno). Sentencia núm. 116/1999. Recurso de inconstitucionalidad 376-1989. Ponente: García Manzano, P. Madrid, 17 de junio de 1999.

ESPAÑA. Tribunal Constitucional (Sala Primera). Sentencia núm. 207/1996. Recurso de amparo 1789-1996. Ponente: Gimeno Sendra, V. Madrid, 16 de diciembre de 1996.

ESPAÑA. Tribunal Constitucional (Sala Segunda). Sentencia núm. 117/1994. Recurso de amparo 2016-1990. Ponente: Gabaldón López, J. Madrid, 25 de abril de 1994. (a) 
ESPAÑA. Tribunal Constitucional (Sala Primera). Sentencia núm. 7/1994. Recurso de amparo 1407-1992. Ponente: Rodríguez-Piñero y Bravo-Ferrer, M. Madrid, 17 de enero de 1994. (b)

ESPAÑA. Tribunal Supremo (Sala de lo Penal). Acuerdo. Madrid, 31 de enero de 2006.

ESPAÑA. Tribunal Supremo (Sala de lo Penal). Sentencia núm. 1311/2005. Recurso de casación 739-2005. Ponente: Martín Pallín, J. A. Madrid, 14 de octubre de 2005. (a)

ESPAÑA. Tribunal Supremo (Sala de lo Penal). Sentencia núm. 501/2005. Recurso de casación 774-2004. Ponente: Delgado García, J. Madrid, 19 de abril de 2005. (b)

ESPAÑA. Tribunal Supremo (Sala de lo Penal). Sentencia núm. 1701/1992. Recurso 4891990. Ponente: Ruiz Vadillo, E. Madrid, 13 de julio de 1992.

TRIBUNAL EUROPEO DE DERECHOS HUMANOS (Gran Sala). Caso S. y Harper contra Reino Unido. Demanda núm. 30562/2004 y 30566/2004. Sentencia de 4 de diciembre de 2008.

TRIBUNAL EUROPEO DE DERECHOS HUMANOS (Gran Sala). Caso Van der Velden contra Países Bajos, 29514/05. Decisión de inadmisión de 7 de diciembre de 2006. 